J. Lake Sci.(湖泊科学), 2008, 20(2): 167-172

http://www.jlakes.org. E-mail: jlakes@niglas.ac.cn

(C)2008 by Journal of Lake Sciences

\title{
Cyanobacteria bloom detection and monitoring from satellite observations in the coastal region of Finland*
}

\author{
ZHANG Yuanzhi ${ }^{1,2} \&$ DUAN Hongtao ${ }^{3}$ \\ (1: Institute of Space and Earth Information Science, The Chinese University of Hong Kong, Shatin, NT, Hong Kong, P.R. China) \\ (2: Laboratory of Space Technology, Helsinki University of Technology, 02610 Espoo, Finland) \\ (3: State Key Laboratory of Lake Science and Environment, Nanjing Institute of Geography and Limnology, CAS, Nanjing 210008, \\ P.R.China)
}

\begin{abstract}
This study investigates and analyses the possibility of cyanobacteria bloom detection as a case study in the Gulf of Finland and southern Finish lakes. The results show that MODIS data are difficult to be used in cyanobacteria bloom early warning. The main reason is that MODIS data are more suitable for CASE I waters as there are five bands in the spectral region of 400-550nm. However, for CASE II waters (estuary, coastal, and lakes), the maxima of reflectance spectra are shifting towards longer wavelengths with increasing turbidity or increasing amount of CDOM. This suggests that the reflectance maximum in coastal waters often occurs in the spectral range of 550-670nm where MODIS data do not have any spectral bands. In contrast, MERIS data have three bands of 560, 620 , and $665 \mathrm{~nm}$ at the spectral region of $550-670 \mathrm{~nm}$. The two bands at $620 \mathrm{~nm}$ and $665 \mathrm{~nm}$ are potentially important bands of detecting cyanobacteria bloom of the coastal waters (and/or lakes). The reason is that there are the phycocyanin absorption near $630 \mathrm{~nm}$ and a reflectance peak near $650 \mathrm{~nm}$. In fact, MODIS and MERIS data are unlikely applicable to warn potentially cyanobacteria bloom in its early stages, but able to monitor the already formed blooms. This methodology of satellite-based observations can be applied to detection and monitoring of cyanobacteria bloom in Lake Taihu and coastal regions of China.
\end{abstract}

Keywords: Cyanobacteria bloom; satellite observations; coastal waters; inland lakes

\section{芬兰海岸带水域蓝藻水华遥感监测 ${ }^{*}$}

张渊智 ${ }^{1,2}$, 段洪涛 ${ }^{3}$

(1: 香港中文大学太空与地球信息科学研究所, 香港沙田)

(2: 赫尔辛基技术大学空间技术实验室, 赫尔辛基 02610 , 芬兰)

(3: 中国科学院南京地理与湖泊研究所湖泊与环境国家重点实验室, 南京 210008)

摘 要: MODIS-Terra 和 MERIS 数据被用于芬兰湾蓝藻水华的监测, 并对两者的性能进行了比较. 研究结果表明: MODIS-Terra 波段设置主要针对一类大洋水体，缺乏预警藻蓝素的有效波段; MERIS 传感器设置了 $620 \mathrm{~nm}$ 和 $665 \mathrm{~nm}$ 波段，基本对应藻蓝素 的吸收峰 $(630 \mathrm{~nm})$ 和反射峰 $(650 \mathrm{~nm})$, 具有蓝藻水华探测的潜力, 但在藻华未成型之前, 海岸带水体不同优势藻类具有相似的 叶绿素特征, 较难辨别蓝藻水华. 总的来说, MODIS 和 MERIS 数据比较困难实现蓝藻水华初期预警, 但可以有效监测已成型 的蓝藻水华. 这一方法可以用于中国太湖或者海岸带水体藻华探测和监测研究.

关键词：蓝藻水华;卫星观测；海岸带水体；内陆湖泊

In recent years, blooms of autotrophic algal and some heterotrophic protists are increasingly reported in the coastal areas and some large lakes in the world and collectively formed as harmful algal blooms(HABs) ${ }^{[1]}$. These blooms are always attributed to two major factors. One is natural process such as circulation, upwelling

* Received: 2007-09-05; Accepted: 2007-11-06. Zhang Yuanzhi, male, born in 1964, PH.D, Professor; E-mail: yuanzhizhang@cuhk.edu.hk. 

relaxation, and/or river flow. The other is eutrophic status resulted from anthropogenic loadings. Although the latter is usually considered as the main reason of all blooms, it is not the case in many instances. In addition, it is commonly accepted that occurrences of these phenomena are increasing over the world's oceans, but the reasons for this apparent increase remain debated and include not only eutrophication but also increased observation efforts in coastal regions, including some large lakes.

Among these algal blooms, cyanobacteria are potentially one of the most interesting organisms in ecological and phycological studies. They are not only the oldest organisms on the planet, but also very important primary-producers. Many of them are potentially toxic, and are often nuisance organisms as candidates for aquatic algal blooms. Therefore, massive blooms of cyanobacteria attract the attention of environmental protection agencies, water authorities, and human and animal health organizations because cyanobacteria can cause a range of amenity, water quality and treatment problems. The issue of cyanobacteria bloom is especially serious in coastal regions of the Baltic Sea and inland lakes in Netherlands and Spain.

Water quality monitoring in coastal regions and lakes using remote measurements at visible and near-infrared(VNIR) wavelengths has been lasted over three decades since the 1970s. Literature suggests that remote sensing technology is able to provide an alternative means for obtaining relative cost, simultaneously information on water quality conditions from coastal waters and in land lakes. Satellite remote sensing is a valuable tool in obtaining information on the processes taking place in the surface of sea and coastal waters. A major advantage of satellite observations over traditional measurements of algal blooms is to provide spatial and temporal domain of their characteristics and distributions. With currently advanced satellite data(e.g., MODIS and MERIS), a large number of variables concerning water quality conditions such as chlorophyll.a(Chl.a), total suspended matter (TSM), yellow substance, turbidity, eutrophication, salinity and sea surface temperature (SST) could be observed on a regular basis ${ }^{[2-3]}$. Although remotely sensed data can provide the synoptic information of surface water quality in coastal regions and lakes, its quantitative use is still a hard task in the study of water quality estimation ${ }^{[4]}$.

There has been a lot of research on algal blooms since the 1960s. They were traditionally studied and performed by taking ship-borne water samples and analysing the samples in the laboratory and/or by doing on-site measurements. However, in order to establish the relationships of optical characteristics and the information of water quality conditions in coastal regions and lakes(CASE 2 water), it is necessary to simultaneously measure spectral information and water sampling in the field for the seasonal and yearly cycles in the study area.

The aim of this study is to estimate whether the spectral resolution of multispectral sensors is adequate for quantitative mapping of cyanobacteria, to evaluate the possibility to separate potential harmful cyanobacteria

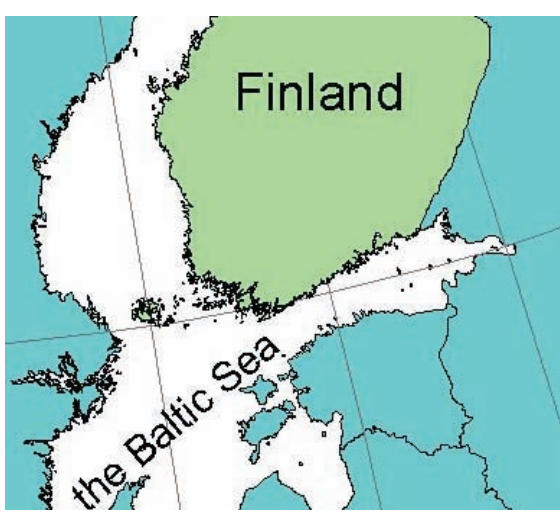

Fig.1 The study area in the coastal region of Finland and Finnish lakes bloom from algae blooms using currently advanced sensors. A bio-optical model is used to simulate just above the water surface reflectance spectra for two different waters and different $\mathrm{Chl}$ concentrations. The spectra were re-sampled to spectral resolution of current satellite sensors to be able to answer these mentioned questions.

\section{Study Area}

The study area is loacted in the coastal regions of Finland and southern Finnish lakes(Fig.1). The Gulf of Finland in the Baltic Sea is relatively shallow, with a mean depth of $38 \mathrm{~m}$ and a maximum depth of $123 \mathrm{~m}$. The total water volume is about $1130 \mathrm{~km}^{3}$. The surface area $\left(29600 \mathrm{~km}^{2}\right)$ is small compared with 
the catchment area $\left(421000 \mathrm{~km}^{2}\right)$. The incoming river discharge is about $110 \mathrm{~km}^{3} /$ year. In the easternmost part of the Gulf the salinity is very low because of the fresh water of the River Neva. The average salinity on the surface is close to $0.6 \%$ in December and $0.3 \%-0.6 \%$ in June. The Gulf is also saline stratified and in summer temperature stratified. In general, most of the Gulf is nitrogen limited, but the inner Neva estuary is phosphorus limited. Therefore, the factors causing increased light attenuation such as organic matter, phytoplankton, and suspended sediments vary temporally as well as spatially ${ }^{[5]}$.

\section{Optical remote sensing of water}

\subsection{Spectral measurements}

Optical remote sensors receive the signal of some portion of the upwelling radiance $L_{\mathrm{u}}(\lambda)$ emerging from the water surface (or water leaving radiance $L_{\mathrm{w}}(\lambda)$ ) and additional radiance from atmospheric scattering (or skylight spectral radiance $L_{\text {sky }}(\lambda)$ ). Therefore, the water leaving radiance will necessarily affect the estimation of water quality variables from remote sensing observations. Water leaving radiance is a function of solar intensity and angle with the time and the inherent optical properties (IOPs) of the water. IOPs are independent of the intensity and geometry of the incoming radiation, but vary in relation to the concentrations of dissolved and suspended materials in the water ${ }^{[6]}$.

Remote sensing reflectance $R_{\mathrm{rs}}(\lambda)$ is the ratio of upwelling radiance $L_{\mathrm{w}}(\lambda)$ leaving a water body to downwelling irradiance $E_{\mathrm{d}}(\lambda)$ impinging on the water body ${ }^{[2]}$

$$
R_{\mathrm{rs}}(\lambda)=\frac{L_{\mathrm{w}}(\lambda)}{E_{\mathrm{d}}(\lambda)}
$$

The remote sensing spectra reflectance $R_{\mathrm{rs}}(\lambda)^{[7-8]}$ is deduced from the following three-step measurements carried out on the ship-side exposed to the sun:

1)The spectral radiance $L_{\mathrm{d}}(\lambda)$ reflected from the total (sun+sky) downwelling radiance, obtained with the detector head pointed on a reflectance spectral standard plate with a reflectance factor $R_{\mathrm{p}}(\lambda)$ between 400-900nm;

2)The spectral radiance of the water surface $L_{\mathrm{u}}(\lambda)$, measured at about $2 \mathrm{~m}$ above the surface with the same detector pointed downward towards nadir (vertically). This operation is repeated about 10 times;

$3)$ The skylight spectral radiance $L_{\text {sky }}(\lambda)$ measured with the same detector pointed vertically towards the sky.

The water leaving radiance $L_{\mathrm{w}}(\lambda)$ is calculated as follows ${ }^{[4]}$.

$$
L_{\mathrm{w}}(\lambda)=L_{\mathrm{u}}(\lambda)-\rho L_{\text {sky }}(\lambda)
$$

where the $\rho$ value is related to the water surface Fresnel reflectance, which can be usually regarded as nearly 0.02 for angles less than $30^{\circ[4]}$.

On the other hand, downwelling irradiance $E_{\mathrm{d}}(\lambda)$ above the water surface is derived from the radiance $L_{\mathrm{d}}(\lambda)$ reflected from the reflectance spectral standard plate ${ }^{[4]}$

$$
E_{\mathrm{d}}(\lambda)=\pi L_{\mathrm{d}}(\lambda) / R_{\mathrm{p}}(\lambda)
$$

During the field spectral measurements, some spectra were eliminated based on the following criteria: 1)Spectra with negative values between $400 \mathrm{~nm}$ and $700 \mathrm{~nm}$; 2)Spectra not similar to others recorded at the same station; 3)Spectra whose shape is similar to the sky radiance.

\subsection{An inverse model from reflectance spectra}

Remote sensing technology for watercolour detection is more and more sophisticated with new satellite sensors. With the advanced sensors, new algorithms and specific processing are required to interpret the sensor signal and to quantify dissolved and particulate matter distributed near the water surface ${ }^{[9]}$. Water colour can be quantified from remote sensing reflectance spectra in situ measurements and from radiance data recorded by satellite sensors. Reflectance spectra vary in terms of two inherent optical properties (IOPs), light absorption 
(coefficient $a(\lambda)$ ) and light backscattering (coefficient $b_{\mathrm{b}}(\lambda)$ ). This quantity is relatively independent of illumination and has often been approximated as an empirical function of two IOPs of natural waters ${ }^{[10]}$

$$
R(\lambda)=f \frac{b_{\mathrm{b}}(\lambda)}{a(\lambda)+b_{\mathrm{b}}(\lambda)}
$$

where: $b_{\mathrm{b}}(\lambda)$ is the backscattering coefficient; $a(\lambda)$ is the absorption coefficient; $\lambda$ is the wavelength; $f$ is an empirical coefficient and here with 0.083 .

Clearly, the relationship between the water IOPs and radiance reflectance shows that (a) the radiance reflectance is greater if the backscattering is greater, and (b) the radiance reflectance is lower if the absorption is greater.

Water reflectance is the actual fraction of incident light reflected from the subsurface of water mass. It is neither the surface reflectance, nor the radiation assessed through land-based features and the surface temperatures measured in the IR bands. These inherent difficulties in watercolour remote sensing create a very complicated problem in algorithm development ${ }^{[11]}$.

Considering optically active matter in the eutrophic water, the two coefficients $(a(\lambda))$ and $\left(b_{\mathrm{b}}(\lambda)\right)$ vary in terms of type and concentration of particles and biological detritus. The biological detritus is assumed to be the component of suspended sediment and heterotrophic organisms. Therefore, the total $a(\lambda)$ and $b_{\mathrm{b}}(\lambda)$ can be separated into the sum of the following elementary coefficients: pure water (w), phytoplankton (p), suspended particles (s), heterotrophic organisms $(\mathrm{h})$ and yellow substance $(\mathrm{y})^{[12-15]}$

$$
\begin{aligned}
& a(\lambda)=a_{\mathrm{w}}(\lambda)+a_{\mathrm{p}}(\lambda)+a_{\mathrm{y}}(\lambda)+a_{\mathrm{s}}(\lambda)+a_{\mathrm{h}}(\lambda) \\
& b_{\mathrm{b}}(\lambda)=b_{\mathrm{bw}}(\lambda)+b_{\mathrm{bp}}(\lambda)+b_{\mathrm{bs}}(\lambda)+b_{\mathrm{bh}}(\lambda)
\end{aligned}
$$

From Equation(4), (5) and(6), the following equation can be obtained

$$
R(\lambda)=0.083 \frac{b_{\mathrm{bw}}+b_{\mathrm{bp}}+b_{\mathrm{bs}}+b_{\mathrm{bh}}}{a_{\mathrm{w}}+a_{\mathrm{p}}+a_{\mathrm{y}}+a_{\mathrm{s}}+a_{\mathrm{h}}}
$$

The absorption and backscattering coefficients are converted to specific absorption and backscattering coefficients, $a^{*}$ and $b_{\mathrm{b}}{ }^{*}$, respectively

$$
a^{*}=a /<i>\text { and } b_{\mathrm{b}}{ }^{*}=b_{\mathrm{b}} /<i>
$$

where $<i>$ is the concentration of the variables.

Transformed Equations(7) and (8) at a given wavelength can be expressed as

$$
R(\lambda)=0.083 \frac{X_{\mathrm{h}} B_{\mathrm{h}}(\lambda)+X_{\mathrm{p}} B_{\mathrm{p}}(\lambda)+X_{\mathrm{s}} B_{\mathrm{s}}(\lambda)+C_{\mathrm{w}}(\lambda)}{X_{\mathrm{h}} A_{\mathrm{h}}(\lambda)+X_{\mathrm{p}} A_{\mathrm{p}}(\lambda)+X_{\mathrm{y}} A_{\mathrm{y}}(\lambda)+X_{\mathrm{s}} A_{\mathrm{s}}(\lambda)+D_{\mathrm{w}}(\lambda)}
$$

31 linear equations are obtained from transformed equations

$$
\begin{aligned}
& \alpha_{\mathrm{p} 1} X_{\mathrm{p}}+\alpha_{\mathrm{s} 1} X_{\mathrm{s}}+\alpha_{\mathrm{y} 1} X_{\mathrm{y}}=\beta_{1}(1: 400 \mathrm{~nm}) \\
& \alpha_{\mathrm{p} 2} X_{\mathrm{p}}+\alpha_{\mathrm{s} 2} X_{\mathrm{s}}+\alpha_{\mathrm{y} 2} X_{\mathrm{y}}=\beta_{2}(2: 410 \mathrm{~nm}) \\
& \alpha_{\mathrm{p} 3} X_{\mathrm{p}}+\alpha_{\mathrm{s} 3} X_{\mathrm{s}}+\alpha_{\mathrm{y} 3} X_{\mathrm{y}}=\beta_{3}(3: 420 \mathrm{~nm}) \\
& \alpha_{\mathrm{p} 31} X_{\mathrm{p}}+\alpha_{\mathrm{s} 31} X_{\mathrm{s}}+\alpha_{\mathrm{y} 31} X_{\mathrm{y}}=\beta_{31}(31: 700 \mathrm{~nm})
\end{aligned}
$$

where $\alpha_{j i}=R_{i} A_{j i}-0.083 B_{j i}$ and $j$ is $p, s, h$ and $y$, respectively. $i$ means band number.

$$
\beta_{i}=0.083\left(C_{\mathrm{w} i}+X_{\mathrm{h}} B_{\mathrm{h}}\right)-R_{i}\left(D_{\mathrm{w} i}+X_{\mathrm{h}} A_{\mathrm{h}}\right)
$$

where $R_{i}$ is the remote sensing reflectance at a given band number $(i), A_{j i}$ is the specific absorption coefficient for 4 components $(j=1-4)$ at a given band number $(i=1-31) . C_{\mathrm{w} i}$ and $D_{\mathrm{w} i}$ are the backscattering and absorption coefficients of water at a band number $i$.

For the heterotrophic cell density value, a number "zero(0)" was entered as an initial value in the Equation (11). Equation (10) can be converted to matrix form as follows: 


$$
\left[\begin{array}{ccc}
\alpha_{\mathrm{p} 1} & \alpha_{\mathrm{s} 1} & \alpha_{\mathrm{y} 1} \\
\alpha_{\mathrm{p} 2} & \alpha_{\mathrm{s} 2} & \alpha_{\mathrm{y} 2} \\
\bullet & \bullet & \bullet \\
\alpha_{\mathrm{p} 31} & \alpha_{\mathrm{s} 31} & \alpha_{\mathrm{y} 31}
\end{array}\right]\left[\begin{array}{c}
X_{\mathrm{p}} \\
X_{\mathrm{s}} \\
X_{\mathrm{y}}
\end{array}\right]=\left[\begin{array}{c}
\beta_{1} \\
\beta_{2} \\
\bullet \\
\beta_{31}
\end{array}\right]
$$

Solutions for the matrix are same as the least square solution for linear equations. This means that the inverse matrix of $[\alpha]$ is required for the final solution. Since $[\alpha]$ is not a square matrix and there is no inverse of $[\alpha]$, the matrix $[\alpha]$ can be changed to a square matrix by the transpose of $[\alpha]$. Therefore, a general solution can be expressed as:

$$
[X]=\left[\alpha^{T} \alpha\right]^{-1}\left[\alpha^{T} \beta\right]
$$

In the case of eutrophic water where one species of phytoplankton is dominant, the above precision of matrix solution can be changed with the specific optical values used in the model. We examined the optical values of species in the eutrophic waters in the inverse model to find out the best matching $R_{r s}$ spectrum comparing with reconstructed remote sensing reflectance spectrum with the above solutions and in situ measurements ${ }^{[16]}$.

In situ measurements are often used to obtain empirical relationship between particle concentrations and reflectance spectra ${ }^{[12]}$. These relationships may then be used to quantify phytoplankton and mineral particles from satellite data, after atmospheric corrections. As a contribution to this effort, in situ measurements and a simple test were carried out in the coastal regions of Finland and Finnish lakes. Reflectance measurements were carried out just above the water surface. This is because high turbidity currently observed in the coast causes a very quick decrease of light below the water surface and underwater measurements in such conditions require a specific instrument that was not available during these measurements.

\section{Results and discussion}

Reflectance spectra were measured and applied by using the inverse modelling to analyse the optical properties for the coastal waters and Finnish lakes. These spectral measurements were re-sampled to MODIS-Terra and MERIS bands, respectively. Figure 2 gives an example of MODIS-Terra imagery to show that MODIS data are incapable of identifying and/or determining cyanobacteria bloom, and also not possible of separating waters dominated by cyanobacteria from waters dominated by other algae species. The probable reason is that MODIS bands are more suitable for CASE I waters as its five bands are in the spectral wavelengths of $400-550 \mathrm{~nm}$. However, for CASE II waters (coastal waters and lakes), the maxima of reflectance spectra are always shifting towards longer wavelengths with increasing turbidity and/or increasing amount of CDOM. This implies that the reflectance maximum in coastal waters and lakes often occurs in the spectral range of 550-670nm where MODIS data do not have spectral bands. Therefore, MODIS data cannot provide any more information from the wavelengths of 550-670nm to detect cyanobacteria bloom.

In comparison, MERIS data have three bands of 560,620, and $665 \mathrm{~nm}$ at the spectral region of 550-670nm. Figure 3 show an example of cyanobacteria bloom detection in the Gulf of Finland. It is clear that two bands at $620 \mathrm{~nm}$ and $665 \mathrm{~nm}$ of MERIS data are potentially important bands of detecting cyanobacteria bloom of the coastal waters (and/or lakes) because there are the phycocyanin absorption near $630 \mathrm{~nm}$ and a reflectance peak near $650 \mathrm{~nm}$. In addition, the bands such as $681 \mathrm{~nm}$ and $708 \mathrm{~nm}$ of MERIS data are probably potential to detect the high amount of phytoplankton since they are chlorophyll-a absorption feature and reflectance spectral peak, respectively. However, reflectance spectra of coastal waters with different dominant algae species are quite similar for chlorophyll concentrations below the limit value of algal blooms. Therefore, MERIS data are unlikely applicable to warn potentially cyanobacteria bloom in its very early stages, however, able to detect the already formed blooms. Further studies are still needed to investigate the capability of cyanobacteria bloom in its later stages. 


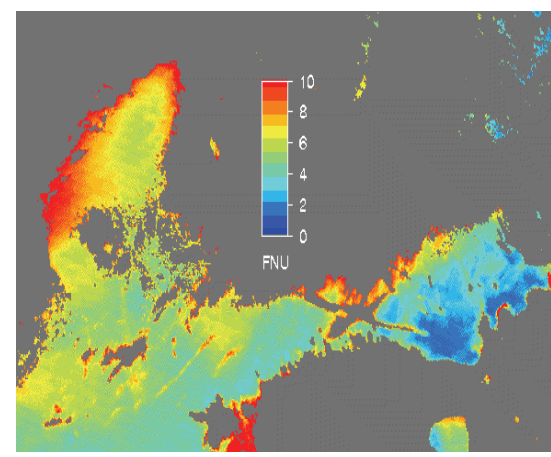

Fig.2 An example of MODIS-Terra data in the Gulf of Finland

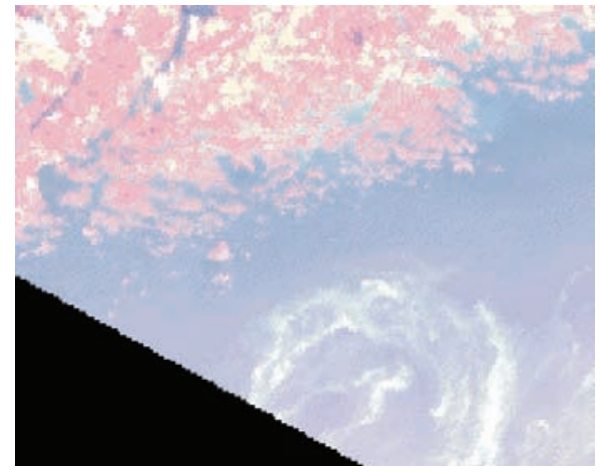

Fig.3 An example of cyanobacteria bloom from MERIS data

Acknowledgements: This study acknowledges the financial support from the Finnish Nessling Fund and the Academy of Finland. The data access to NASA and ESA is highly appreciated.

\section{References}

[1] Sellner KG, Doucette GJ, Kirkpatrick GJ. Harmful algal blooms:causes, impacts and detection. J Ind Microbiol Biotechnol, 2003, 30: 383-406

[2] Lindell TD, Pierson D, Premazzi G et al. Manual for monitoring European lakes using remote sensing techniques. Luxembourg: Official Pulications of the European Communities, 1999.

[3] Zhang Y, Pulliainen J, Koponen S et al. Application of an empirical neural network to surface water quality estimation in the Gulf of Finland using combined optical data and microwave data. Remote Sens Environ, 2002, 81: 327-336.

[4] Zhang Yuanzhi, Pulliainen JT, Koponen SS et al. Water quality retrievals from combined Landsat TM data and ERS-2 SAR data in the Gulf of Finland. IEEE Trans Geosci Remote Sens, 2003, 41: 622-629.

[5] Kuusisto M, Koponen J, Sarkkula J. Modelled phytoplankton dynamics in the Gulf of Finland. Enviorn Modelling and Software, 1998, 13: 461-470.

[6] Mobley CD. Estimation of the remote-sensing reflectance from above surface measurements. Appl Optics, 1999, 38: 7442-7455.

[7] Lee ZP, Carder KL, Peacock TG et al. Method to derive ocean absorption coefficients from remote-sensing reflectance. Appl Optics, 1996, 35: 453-462

[8] Froidefond JM, Gardel L, Guiral D et al. Spectral remote sensing reflectance of cosatl waters in French Guiana under the Amazon influence. Remote Sens Enviorn, 2002, 80: 225-232.

[9] Sathyendranath S. Remote sensing of ocean colour in coastal and other optically-complex. Waters IOCCG Report, $2000,3$.

[10] Kirk JTO. Light and photosynthesis in aquatic ecosystems. Massachusetts: Cambridge Press, 1994.

[11] Ahn YH. Development of an inverse model from ocean reflectance. Marine Techn Society J, 1999, 33: 69-80.

[12] Morel A, Prieur L. Analysis of variation in ocean color. Limn \& Oceang, 1977, 22: 709-722.

[13] Gordon HR, Brown OB, Evans RH et al. A semi-analytical radiance model of ocean color. J Geophys Res, 1988, 93: 10909-10924.

[14] Prieur L, Sathyendranath S. An optical classification of coastal and oceanic waters based on the specific spectral absorption curves of phytoplankton pigments, dissolved organic matter and other particulate materials. Limn \& Oceang, 1981, 26: 671-689.

[15] Bukata RP, Jerome JH, Kondratyev KYA et al. Optical properties and remote sensing of inland and coastal waters. Boca Raton, Florida: CRC Press Inc, 1995.

[16] Curran PJ, Novo EMM. The relationship between suspended sediment concentration and remotely sensed spectral radiance: a review. J Coastal Res, 1988, 4: 205-216. 